\title{
Blunt Abdominal Trauma Leading to Pancreatic Injury in Childhood. Delay in Diagnosis Leads to Poor Outcomes-A Case Presentation
}

\author{
Zohaib A. Siddiqui' ${ }^{1}$, Fahd Husain ${ }^{2}$, Midhat N. Siddiqui ${ }^{3}$ \\ ${ }^{1}$ King's College London, London, UK \\ ${ }^{2}$ Darent Valley Hospital, Dartford, UK \\ ${ }^{3}$ Lewisham and Greenwich NHS Trust, Queen Elizabeth Hospital, London, UK \\ Email: zohaib.siddiqui@kcl.ac.uk
}

How to cite this paper: Siddiqui, Z.A., Husain, F. and Siddiqui, M.N. (2016) Blunt Abdominal Trauma Leading to Pancreatic Injury in Childhood. Delay in Diagnosis Leads to Poor Outcomes-A Case Presentation. International Journal of Clinical Medicine, 7, 809-813.

http://dx.doi.org/10.4236/ijcm.2016.712087

Received: September 3, 2016

Accepted: November 27, 2016

Published: November 30, 2016

Copyright $\odot 2016$ by authors and Scientific Research Publishing Inc. This work is licensed under the Creative Commons Attribution International License (CC BY 4.0).

http://creativecommons.org/licenses/by/4.0/

\begin{abstract}
This case report illustrates the difficulty in diagnosing paediatric patients with life threatening pancreatic injuries. A high index of suspicion is essential as late diagnosis significantly affects outcomes. A 9-year-old child presented with epigastric pain following an accident on his pushbike. The patient was examined in paediatric accident and emergency (A/E) and was discharged. He returned twice more to A/E and on the third visit, 5 days after the initial incident, a CT scan was performed. This showed a classical injury to the body of the pancreas with a collection in the lesser sac. The patient was transferred to the regional hepato-pancreato-biliary unit (HPB unit) and underwent surgery. Pancreatic injuries can be difficult to detect clinically and patients may be well on initial presentation with normal observations and routine bloods. Early CT scanning confirms the diagnosis and results in early specialist referral and better outcomes.
\end{abstract}

\section{Keywords}

Paediatric Trauma, Blunt Abdominal Injury, Pancreatic Injury

\section{Introduction}

Blunt abdominal injury in paediatric patients is the primary mechanism for pancreatic injury. These injuries can lead to serious morbidity. The pancreas is a retroperitoneal structure and can be injured in blunt trauma to the epigastrium. These patients may initially present with minimal clinical signs. It has also been documented that complaints from paediatric patients are commonly unspecific; thus, the diagnosis is often delayed and therefore so is the treatment resulting in poorer outcomes. A high level of 
suspicion is essential for early diagnosis and improved outcomes. Imaging is essential as all other tests are non-specific. At initial presentation abdominal examination may be unremarkable due to the retroperitoneal nature of the pancreas. Routine blood tests at presentation including amylase may be normal in major pancreatic trauma. A FAST scan in A/E may be useful but as demonstrated in this case was misleading. CT scan remains the gold standard for imaging the pancreas and other abdominal viscera. This paper highlights the importance of having a high index of suspicion for pancreatic injury in blunt abdominal trauma to the abdomen.

\section{Case Presentation}

A 9-year-old boy presented to paediatric A/E with abdominal pain. He was brought by his mother who gave a six-hour history of the child falling over the handlebar of his pushbike. He was complaining of abdominal pain and had vomited four times. He was assessed and found to have tenderness and bruising to the epigastric area. His vital signs were normal and he was discharged without a diagnosis or investigations.

Following discharge he continued to have abdominal pain and felt nauseated. As his symptoms failed to settle on day 3 his mother brought him to the A/E again. He continued to suffer with upper abdominal pain and gave a history of one vomit with no blood. According to his mother he was refusing to eat or drink. General examination was unremarkable, but he remained tender in the upper abdomen. On this occasion plain chest and abdominal films were performed and appeared normal. Respiratory rate was 26 , pulse 97 , Blood pressure was $119 / 79$ and temperature was $37.1^{\circ} \mathrm{C}$ with oxygen saturation of $100 \%$ on air. Urinalysis was negative for blood. No blood were undertaken and he was discharged on Ibuprofen with a diagnosis of soft tissue injury.

He re-presented 48 hours later having been referred by his General Practitioner who was concerned about this child's severe epigastric pain and a history of vomiting on ten occasions since his initial injury. In $\mathrm{A} / \mathrm{E}$ he appeared unwell, dehydrated and in pain. He had only passed urine once in the last 24 hours. On examination his pulse was $98 /$ minute, temperature was $37.8^{\circ} \mathrm{C}$, saturation remained $100 \%$ on air. He was tender in the epigastrium. He was referred to the on call general surgeons who arranged for blood tests and an urgent CT scan of the abdomen and pelvis. His Haemoglobin was 116 g/L, WBC 79, C Reactive Protein (CRP) 95 mg/L, Liver function tests were normal, however his serum Amylase was $1049 \mathrm{U} / \mathrm{L}$. The CT scan demonstrated a classical injury to the body of the pancreas with a collection in the lesser sac (Figure 1). The patient was resuscitated and referred to the regional paediatric hepato-pancreato-biliary unit (HPB unit). There he underwent laparoscopic surgery, debridement and drain placement. He also required endoscopic stenting of the pancreatic duct. He had a slow postoperative recovery and was discharged 12 weeks later. Although he has made a good recovery he continues to be troubled by mild non-specific upper abdominal pain.

\section{Discussion}

Blunt trauma to the upper abdomen is a frequent cause of presentation to the 


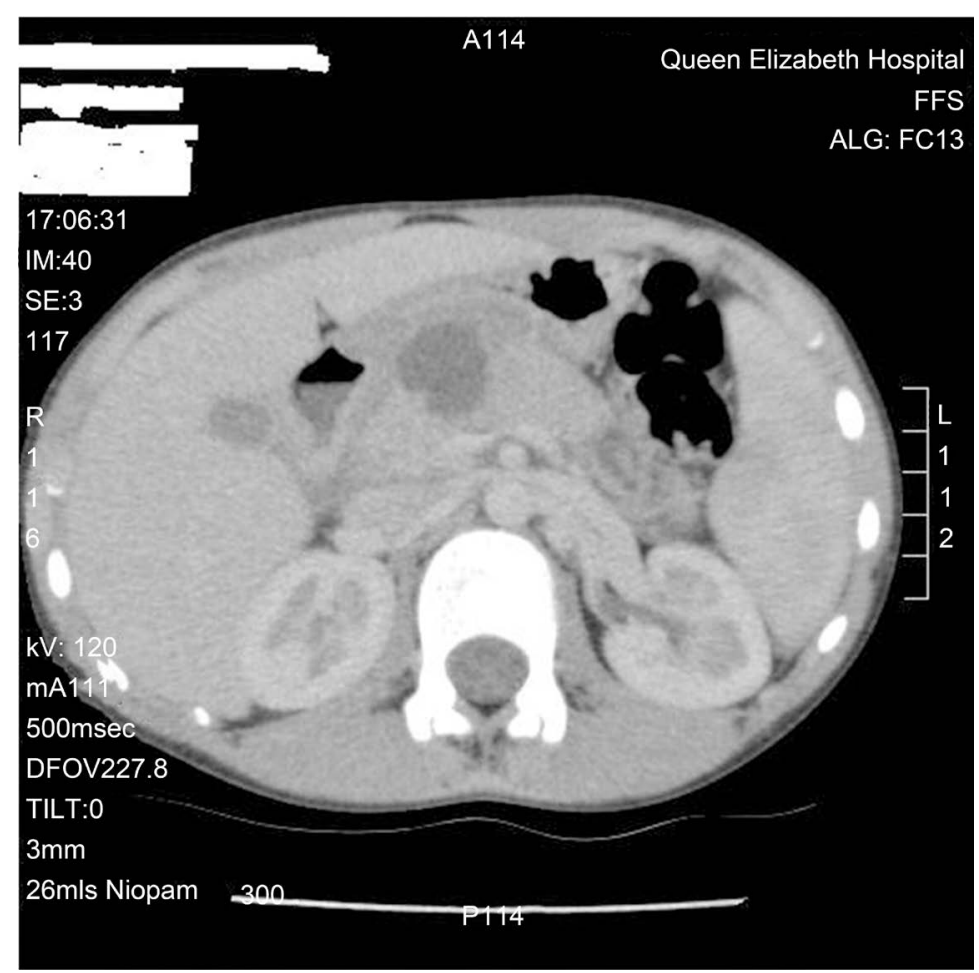

Figure 1. CT scan showing a classical injury to the body of the pancreas with a collection in the lesser sac.

emergency department. In children the abdomen is the second most common site of injury [1].

In blunt abdominal trauma, the visceral organs are commonly injured where the spleen and liver are the two most frequently damaged [2]. However injuries to the pancreas are important as they can be missed on initial examination which leads to significant morbidity [2].

Blunt trauma to the upper abdomen compresses the body of the pancreas against the spine resulting in injury [3]. Bicycle handlebar injuries are a classic cause of pancreatic injuries [4].

Presentation as in this case may be delayed because the pancreas is a retroperitoneal structure and following an injury the collection is contained in the retro-peritoneum and/or lesser sac. As a result the clinical presentation can be misleading as the patient may not have many clinical signs on initial examination [5].

We report this interesting case of a child with a pancreatic injury and want to raise awareness of the presentation and lack of clinical signs on initial presentation and examination. Ultrasound scanning may be diagnostic however during the initial presentation the ultrasound may be normal. Imaging modalities such as CT scans are essential for diagnosis [6] [7] [8] and blood tests including CRP, serum Amylase and WBC may help in the diagnosis; studies have shown that serum amylase and lipase are not reliable or cost effective as screening tools but may support clinical suspicions in the diagnosis of paediatric pancreatic trauma [9]. MRI scanning may be an alternative to CT [10], but 
is more difficult to organise out of hours and less well tolerated in the paediatric age group.

A high index of suspicion is essential as delay in diagnosis increases morbidity. Early diagnosis ensures these life-threatening injuries are appropriately treated in a timely fashion. Initial imaging may be negative and repeat scanning is recommended if clinically appropriate. All such injuries should be referred to the regional HPB unit.

\section{Conclusions}

Blunt abdominal trauma is a common cause for paediatric admissions to $\mathrm{A} / \mathrm{E}$.

The pancreas is a retroperitoneal structure; therefore, clinical signs may be absent on initial presentation. Early investigations including FAST scans and routine blood tests may be normal. A high index of suspicion is essential. CT scan is the investigation of choice. Early diagnosis improves outcomes. All doctors dealing with paediatric emergencies should understand the mechanism of injury to the pancreas and other retroperitoneal organs. Early referral to regional HPB centres is essential to improve outcomes in paediatric pancreatic injuries. Delay in diagnosis has a significant risk of increased morbidity and mortality.

\section{Acknowledgements}

Open access for this article was funded by King's College London.

\section{References}

[1] Sivit, C.J. (2009) Imaging Children with Abdominal Trauma. American Journal of Roentgenology, 192, 1179-1189. http://dx.doi.org/10.2214/AJR.08.2163

[2] Coleman, J.J. (2015) Blunt Abdominal Trauma. In: Common Surgical Diseases, Springer, New York, 49-50. http://dx.doi.org/10.1007/978-1-4939-1565-1_12

[3] Arkovitz, M.S., Johnson, N. and Garcia, V.F. (1997) Pancreatic Trauma in Children: Mechanisms of Injury. Journal of Trauma and Acute Care Surgery, 42, 49-53. http://dx.doi.org/10.1097/00005373-199701000-00009

[4] Clarnette, T.D. and Beasley, S.W. (1997) Handlebar Injuries in Children: Patterns and Prevention. Australian and New Zealand Journal of Surgery, 67, 338-339. http://dx.doi.org/10.1111/j.1445-2197.1997.tb01986.x

[5] Wegner, S., Colletti, J.E. and Van Wie, D. (2006) Pediatric Blunt Abdominal Trauma. Pediatric Clinics of North America, 53, 243-256. http://dx.doi.org/10.1016/j.pcl.2006.02.002

[6] Sivit, C.J., Eichelberger, M.R., Taylor, G.A., Bulas, D.I., Gotschall, C.S. and Kushner, D.C. (1992) Blunt Pancreatic Trauma in Children: CT Diagnosis. American Journal of Roentgenology, 158, 1097-1100. http://dx.doi.org/10.2214/ajr.158.5.1566674

[7] Rekhi, S., Anderson, S.W., Rhea, J.T. and Soto, J.A. (2010) Imaging of Blunt Pancreatic Trauma. Emergency Radiology, 17, 13-19. http://dx.doi.org/10.1007/s10140-009-0811-0

[8] Venkatesh, S.K. and Wan, J.M. (2008) CT of Blunt Pancreatic Trauma-A Pictorial Essay. European Journal of Radiology, 67, 311-320. http://dx.doi.org/10.1016/j.ejrad.2007.07.003

[9] Adamson, W.T., Hebra, A., Thomas, P.B., Wagstaff, P., Tagge, E.P. and Othersen, H.B. (2003) Serum Amylase and Lipase Alone Are Not Cost-Effective Screening Methods for Pediatric Pancreatic Trauma. Journal of Pediatric Surgery, 38, 354-357. 
http://dx.doi.org/10.1053/jpsu.2003.50107

[10] Bosboom, D., Braam, A.W., Blickman, J.G. and Wijnen, R.M. (2006) The Role of Imaging Studies in Pancreatic Injury Due to Blunt Abdominal Trauma in Children. European Journal of Radiology, 59, 3-7. http://dx.doi.org/10.1016/j.ejrad.2006.03.010

\section{Submit or recommend next manuscript to SCIRP and we will provide best service} for you:

Accepting pre-submission inquiries through Email, Facebook, LinkedIn, Twitter, etc. A wide selection of journals (inclusive of 9 subjects, more than 200 journals)

Providing 24-hour high-quality service

User-friendly online submission system

Fair and swift peer-review system

Efficient typesetting and proofreading procedure

Display of the result of downloads and visits, as well as the number of cited articles

Maximum dissemination of your research work

Submit your manuscript at: http://papersubmission.scirp.org/

Or contact 1ijcm@scirp.org 